\title{
Experience in creating a soil-reclamation map of the Zarafshan river valley based on the system analysis of lithodynamic flow structures
}

\author{
Naila Sabitova ${ }^{1}$, Oykhumor Ruzikulova ${ }^{2 *}$, Ilhomjon Aslanov ${ }^{2 *}$ \\ ${ }^{1}$ National University of Uzbekistan, 2 University str, Tashkent, Uzbekitan. \\ ${ }^{2}$ Tashkent Institute of and Agricultural Mechanization Engineers, 39 Qori-Niyoziy str, Tashkent, \\ Uzbekitan
}

\begin{abstract}
Analysis of lithodynamic flows and soil-reclamation studies, based on the plastic relief map, allowed for a systematic analysis of the main components of the natural environment. The ways of migration of chemical elements in the soil are established. For the first time, causal relationships of spatial differentiation of the degree and chemical composition of saline soils in the Zarafshan river valley were revealed. The Zarafshan river basin has a clearly defined border, as we can judge from the map of plastic relief made up in 1: 100000 scale. Here three cascade systems are well distinguished, which is very important for the formation of the reclamation state of the territory. In this area, that is, the subsystem, on the proluvial-alluvial deposits is the main volume of groundwater, which is closely related to the surface. This subsystem is part of the catchment area of the Zarafshan river basin, which is the main source of removal from the territory of a huge mass of dissolved and solid substances.
\end{abstract}

Keywords. Plastic relief, lithodynamic flow structures, chemical composition and salinization of soils, system analysis, soil reclamation map.

\section{Introduction}

Irrigated agriculture, in particular, the cotton growing zone occupies a special place in the Middle and lower Zarafshan valley. (Fig.1). Over the past 15-20 years, under the influence of the current water management situation, there has been an increase in the process of salinization and erosion, deterioration of water quality, which led to the degradation of irrigated soils. Every year, the area of near lying mineralized groundwater increases. This situation is typical not only for the Zarafshan river valley, but also for the entire Republic. For example, of the water resources used in the national economy in the amount of $60.6 \mathrm{~km} 3,54.8 \mathrm{~km} 3$ or $90.4 \%$ of water is spent on irrigation of crops. [9]. According to the «Waterproject» Association, only 40\% of the water taken from water sources reaches the plants, and the rest of it is lost in the irrigation network $(-40 \%)$ and

*Corresponding authors: oyhumor.ruzikulova@gmail.com, ilhomaslanov@tiiame.uz 
during irrigation $(-20 \%)$. More than $60 \%$ of the total water loss forms a return flow. The area of irrigated land in need of drainage is 3.3 million hectares in Uzbekistan, of which 2.4 million hectares are provided with horizontal wells and 0.4 million hectares with vertical wells. Closed horizontal drainage is built on an area of 580 thousand hectares - this is less than $18 \%$ of the total area in need of drainage [1]. Large investments in the reconstruction and construction of the collector-drainage network, water costs for annual washing of saline lands in the amount of $12-13 \mathrm{~km} 3$ are ineffective. Studies have shown that the area of medium and highly saline land is continuously increasing.

Analysis of domestic and foreign experience of land irrigation has shown that the effectiveness of water reclamation is largely determined by the completeness of accounting for all the main natural factors that determine the degree of salinity. The optimal water-salt regime of saline soils is achieved by carefully taking into account the natural features of the territory: the degree of its natural drainage, salinity of soils in the aeration zone, mineralization and pressure of groundwater, mechanical composition and lithological structure of soils in the saturation zone. Not unimportant is also the correct understanding of the structure of the surface of the territory. Under the influence of endogenous and egzogenous processes, the formation of relief forms of convex and concave (increases and decreases) occurs. These forms of relief in the form of lithodynamic flows are reflected on the map of plastic relief. These forms determine the direction and speed of surface and subsurface, as well as biogeochemical runoff-the result of the influence of the gravitational field. The organization of irrigation, taking into account the above provisions, creates an optimal-rational water-salt regime that provides maximum salinity of saline soils and desalination of groundwater with minimal labor costs and scarce irrigation water. To achieve this goal, it is necessary to conduct comprehensive research based on a systematic analysis of the study area, which is relevant.

\section{Research area}

The object of study is the soil geosystems of the Zarafshan valley. The Zarafshan valley is characterized by a high natural discharge dynamic [5]. in the mountainous upper part located Tajikistan. Middle and lower part located Uzbekistan (Fig 1).

The research objective is to study the spatial differentiation of salts in soils within the geosystems of the Zarafshan river valley.

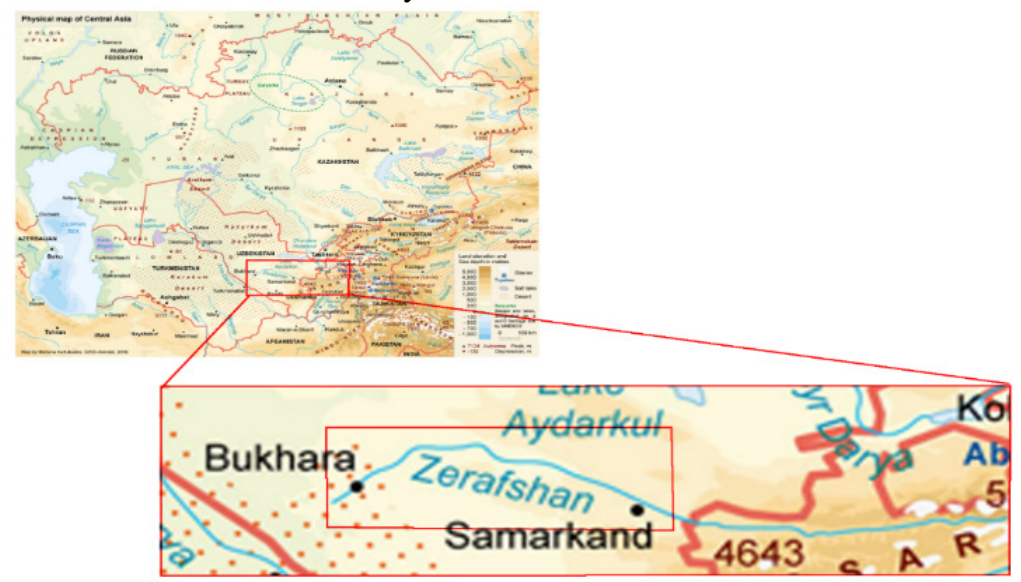

Fig. 1. Middle and lower part of the Zarafshan river basin 


\section{Data and Methods}

In the study of soil salinization [12] system-structural, comparative-geographical, soilgeographical, soil-geochemical and laboratory-analytical methods, interpretation of aerial photographs, methods of key sites and expert-analytical assessments of the current reclamation state of irrigated soils were used [16]. The soil-reclamation map is based on the map of plastic relief [21].

Stock and published materials, as well as the results of field research, were used as factual material in the preparation of the soil-reclamation map. Full-scale observations were carried out to identify the dynamics of changes in the depth and chemical composition of groundwater, as well as the degree and type of salinization, the content of water-soluble and toxic salts in irrigated soils. To study the process of salt migration and identify their spatial distribution, the objects in the basin of the river were selected [22]. Zarafshan consists of 10 reference (key) farms, including 5 in the second (middle part) (Samarkand basin) and 5 in the third segment (Bukhara and Navoi-Kanimeh). On the reference farms, full-scale studies were carried out using the salt survey method (key sites) on a scale of 1: 10000. In total, 69 main soil sections were laid on the study area and in addition, several auxiliary intermediate pits of the second order (up to $1 \mathrm{~m}$ ). about 350 soil samples, 32 ground samples and about 30 irrigation and collector-drainage water samples were taken from them, which were examined in the analytical center of the Institute. In the main reference sections, the description of the morphological structure of soils on genetic horizons was performed, and in 15 of the most typical ones, the determination of the volume weight of soil-soils by the cylinder method, in three - five times repetitions, and in some workings water-physical properties were studied [23].

\section{( Results}

Analyses of water extract of type I and II were carried out with the determination of the entire composition of easily soluble salts-the dense residue (the sum of salts), $\mathrm{CO}_{3}, \mathrm{HCO}_{3}$, $\mathrm{CI}, \mathrm{SO} 4, \mathrm{Ca}, \mathrm{Mg}$, which allowed us to obtain the most detailed characteristic of saline soils. In the selected soil samples, the quantitative content and qualitative composition of salts, the degree and type of salinization were determined, the reserves of water-soluble salts were determined by genetic horizons and by layers $0-1,1-2 \mathrm{~m}$ and $0-2 \mathrm{~m}$. Laboratory studies of saline soils were conducted in the analytical center of the research Institute of soil Science and Agrochemistry (Tashkent, Uzbekistan).

The obtained data are used in the preparation of the soil-reclamation map (fig) valley of the river Zarafshan. The morphological basis of the soil-reclamation map, when conducting field research, as well as analysis of the actual material was a map of plastic relief (landforms). The map is made up by establishing the most clearly defined boundaries between the systems of convex and concave forms of relief. This method made it possible to display flow structures on maps, which are essentially geochemical flows that carry information about the reclamation state of the studied territory. The flow structures selected on the map made it possible to determine the areas of formation, transit and discharge of salts, since the main organizational unit of the entire system of contours of the relief plastic map is a catchment basin of any order. It is known that the basins of the geosystems there is an absolute predominance of not strictly horizontal, but inclined movements of water and solid masses from higher to lower levels. As a result, the basin territory is dynamically interfaced with horizontal migration flows. The studied territory, the Zarafshan river basin has clearly defined borders, where three cascade geosystems are well distinguished, which is very important for the reclamation assessment of the studied territory. 
The Zarafshan river basin has a clearly defined border, as we can judge from the map of plastic relief made up in 1: 100000 scale. Here three cascade systems are well distinguished, which is very important for the formation of the reclamation state of the territory. The upper part of the studied territory is occupied by the basins of the upper arms of the Zarafshan river, which is formed at the fork of the spurs of the Turkestan, Zarfshan and Hissar ridges. This is the inner mountain part of the valley the width of which in the upper part does not exceed $2 \mathrm{~km}$ and in the area of the Panjiken corridor reaches up to $12 \mathrm{~km}$. In this area, that is, the subsystem, on the proluvial-alluvial deposits is the main volume of groundwater, which is closely related to the surface. This subsystem is part of the catchment area of the Zarafshan river basin, which is the main source of removal from the territory of a huge mass of dissolved and solid substances.

The second, that is, the middle part of the basin-the Samarkand basin, lies sub-latitude between the Panjikent intermountain corridor in the East and Karmaninsky in the West and is surrounded by mountain systems. The valley of the Zarafshan river has, as can be seen on the map, a single stream structure in the form of "bulbs". The valley itself is composed of numerous "bulbs", that is, subsystems that are closely Packed together. Such a complex and natural structure of stream structures is associated with the morphology of the relief and it is a pronounced form of abstract geological formations, which form the soil cover with their inherent reclamation features. The overall slope of the average subsystem of the Zarafshan river basin is insignificant-0.004-0.008 $\mathrm{m}$. the main area of irrigated land is concentrated here. In the Meridian city of Juma, the strip of irrigated land reaches the greatest width and gradually moves in the direction of the Karmaninsky corridor. On the studied subsystem, ground and surface waters are closely interconnected and directed to the riverbed. In the Central part, they coincide with the direction of irrigation water flows. Ground water is fresh, hydrocarbonate-sulphate. The relatively deep occurrence and rather low mineralization of groundwater in irrigated soils is explained by the fact that the relief and geomorphological conditions here contribute to a better outflow of groundwater. Dominated by the process of natural desalinization of soils.

The lower, third section of the Zarafshan basin is a huge Delta plain. As can be seen from the map, starting from the Karmaninsky corridor, the flows fan out to the West and South-West, and in the extreme West, wide flow structures come out to the modern AmuDarya valley. The flows of matter coming from above accumulate within it, thus the subsystem is located in the zone of accumulation of water-soluble salts.

The analysis of the actual field material showed that the heterogeneity of geosystems-basins is manifested in the lithological-facies composition, geofiltration and geophysical properties, the intensity of water exchange in the aeration zone, which leads to salinization of soils and increased mineralization of groundwater. On the map (Fig.2.) each area is heterogeneous and reflects the vector movement of the soil-geological mass under the influence of the earth's gravity field.

Flow structures on the map show that against the background of the General slope of the relief and the composing geological bodies, there is a concentrated movement of matter and energy of different Genesis. It is known that basins are characterized by an absolute predominance of not strictly horizontal, but inclined movements of water and solid masses from higher to lower levels. As a result, the basin territory is dynamically interfaced with horizontal migration flows. We know that in the tops of the removal cone and its periphery, the soils constantly become heavy and saline, the depth of the ground water level decreases and their consumption for surface evaporation increases, which leads to intensive salt accumulation in the soils. 


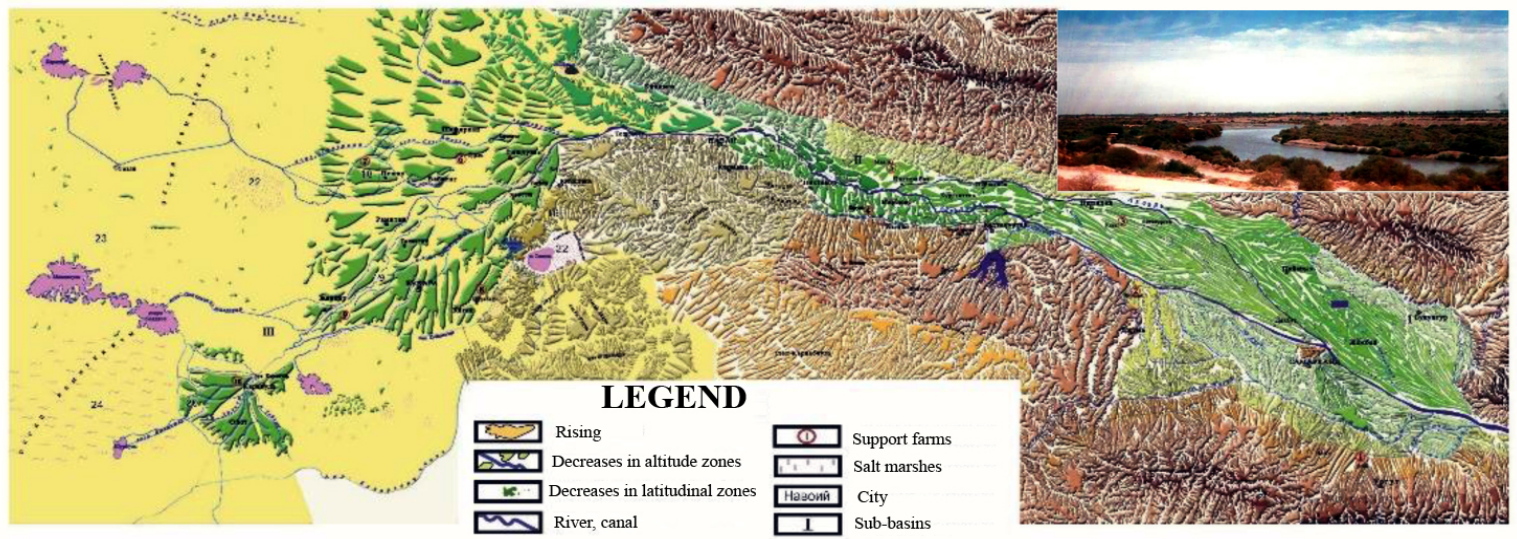

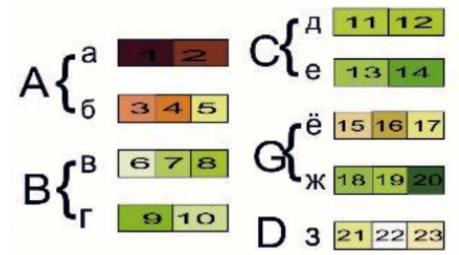
A. Geosystems of the highlands. Erosion-tectonic surface: a- dark brown soil.
Vegetation xerophytes, grassy and shrubbery; b- low mountains, in the foothills Brown soil Rainfed, virgin lands. Vegetation: ephemera, walnut
B. Geosystems of the foothills and foothill plains. Brown soil Vegetation upland xerophytes,
g-sloping and flat proluvial plains Accumulated terraces, irrigated and virgin lands
C. Geosystems of residual surfaces; d- relatively ancient surfaces. Ancient takeaway cones and
river terraces. Gray-brown lands. Vegetation: ephemeroids, sedge sand, bluegrass viviparous, etc.
river terraces. Gray-brown lands. Vegetation: ephemeroids, sedge sand, bluegrass viviparous, etc.
Perennial shrubs-boyalich, Biyurgun, etc. e-medium saline ancient irrigated lands on the I, II, III terraces of the Zarafshan River.
Perennial shrubs-boyalich, Biyurgun, etc. e-medium saline ancient irrigated lands on the I, II, III terraces
G. Geosystems. Aeolian-denudation surfaces, e-low mountains, takyrs. The soil is gray-brown, saline;
vegetation squirrel forests, psammophytic-shrub complexes
D. Geosystems of the alluvial delta, hollows and depressions, modern irrigated delta
Non-saline and medium-saline. Alluvial gray earth soils; $\mathbf{w}$-ancient irrigated soils

Fig. 2. Soil-reclamation map of the middle and lower part of the Zarafshan river basin 
According to the geometric shape of flow structures, it is possible to distinguish the boundaries of geosystems within which there is a sharp change in the reclamation state of soils.

The chemistry of salinization of ground water in the majority of cases is chloridesulphate and sulphate, magnesium-sodium, magnesium-calcium and calcium-magnesium. The qualitative composition of the salts is dominated by sodium sulfates (Na2S04) magnesium (MgS04), a fairly high proportion of calcium sulfate (CaS04), less than calcium bicarbonate $(\mathrm{Ca}(\mathrm{HCO} 3) 2)$. The accumulation of sulfates at low levels of mineralization of groundwater is quite intense and its content increases in a straight line depending on the increase in mineralization to about 5-6 g/l. Further, the rate of increase in the concentration of sulfates slows down. The formation of gypsum $(\mathrm{CaS} 04 * 2 \mathrm{H} 20)$ and sodium sulfates (Na2SO) of magnesium (MgSO4) is observed.

In the area of Navoi, the valley expands somewhat (Navoi-Kanimeh oasis). The studied soils on the key site are old-irrigated, gray-earth-meadow, meadow, alluvial-saz, mainly medium-loamy, to varying degrees' saline, composed of proluvial-alluvial and alluvial deposits. Observations have shown that the level of ground water on the studied irrigated massifs in recent years has risen almost 1.0-1.5 m. the Seasonal amplitude ranges from 0.8$1.2 \mathrm{~m}$. the Mineralization of groundwater 1-3 and 3.0-3.5 g/l. A natural relationship between the salt composition of soils and the degree of mineralization of groundwater was revealed. The content of chlorine, sodium and magnesium in the studied groundwater increases in parallel with the increase in mineralization. Accumulation of $\mathrm{Na}$ and $\mathrm{CI}$ occurs mainly in the form of $\mathrm{NaCI}$. The third lower sub-basin after about $50 \mathrm{~km}$ between Kesilapanku Automatischem and plateau moves in the Bukhara oasis. The key site in the Bukhara oasis, located on a low-flow area, is highlighted on the map in the form of a triangular shape. Soils old and new-irrigated, meadow and takyr, desert, medium-and lightloamy, varying degrees of salinity. They are composed of sand-loam and clay alluvial deposits and agroirrigation sediments with a capacity of up to 5-10 m. they are Developed on the ancient seaboard (ancient cone of the Zarafshan river) plain and on the P-floodplain terrace. Here begins the ancient Bukhara cone of removal, the width of which in the area of Bukhara reaches $60-65 \mathrm{~km}$. Field observations have shown that groundwater, depending on the terrain, lies at various depths from 56 to $320 \mathrm{~cm}$. They have a generally established character with seasonal highs at depths of $0.52 .0 \mathrm{~m}$, and lows of 2.5-3.2 m, the amplitude of oscillations is on average 1.2-1.5 m. The degree of mineralization of groundwater varies greatly. In Navoi-Kanimeh oasis, it ranges from 2 to $10 \mathrm{~g} / \mathrm{l}$, in Bukhara-from 1.7 to 11.2 and Karakul - from 3 to $12 \mathrm{~g} / 1$.

West of the railway station Yakka-tut the valley is compressed by the exits of tertiary rocks, where it passes into the Karakul oasis-the fourth subbasein, which occupies the lower position in relation to the upper floors of the river basin. The streams of matter coming from above are deposited within it, thus the subsystem is predisposed to the accumulation of water-soluble salts. Here, the mineralization of groundwater in fallow and empty peripheral areas increases to $20-50 \mathrm{~g} / 1$ or more. As can be seen from the presented map, starting from the Karmaninsky corridor, the flows fan-like expand to the West and SouthWest, and in the extreme West, wide flow structures go out to the modern Amu Darya valley. The difference in the amplitude of altitudes within the plain part of the valley from Karmadonskom of the corridor to the bed of the Amudarya is 190-200 m. the Terrain is flat and low-lying parts of the subsystems local pool is broken inside the basin depressions Agitminski, Karakirski, Dengizkulsky basins etc. They are used to collect collector and drainage water diverted from the irrigated area. Soils are old - irrigated meadow alluvial desert, medium-loamy, medium-and highly saline. They are composed of loamy-clay-sand alluvial and agroirrigation deposits, mainly sand and pebble layers. 
In irrigated fields, spotty salinization is widespread, and in non-irrigated fields, there is a sudden salinization. Convex and concave forms on the compiled soil-reclamation map explain the pattern of distribution of spotted salinization. They are located on the concave structures of the selected streams. Depending on the shape of the terrain, the degree of artificial and natural drainage of the territory, the type of cultivated crops, groundwater lies at different depths. During the growing season, ground water lies from 0.50 to $2.10 \mathrm{~m}$ and from $2.50-3.20 \mathrm{~m}$ - in non-vegetative, and their mineralization ranges from poorly mineralized to highly mineralized (10-12 g/l).

The chemistry of salinization of ground water in the pre-fertile majority of cases is sulphate and chloride-sulphate, rarely sulphate-chloride. The qualitative composition of the salts is dominated by sodium sulfates (NaSO4) and magnesium (MgS04), a high proportion of calcium sulfate ( $\mathrm{CaS04})$. As the salt concentration increases, the content of chloride salts $(\mathrm{NaCl})$ increases. $\mathrm{CaCl} 2$ and $\mathrm{MgCl} 2$ salts were detected in separate groundwater samples. Moderate hydromorphic humidification from the ground water lying above the "critical depth", high temperature and dryness of the air at a relatively high wind activity of the territory leads to a wide development of the saline process.

\section{Conclusion}

The upper part of the studied territory is occupied by the basins of the upper arms of the Zarafshan river, which is formed at the fork of the spurs of the Turkestan, Zarfshan and Hissar ridges. This is the inner mountain part of the valley the width of which in the upper part does not exceed $2 \mathrm{~km}$ and in the area of the Panjiken corridor reaches up to $12 \mathrm{~km}$. System analysis of lithodynamic flow structures and conducted full-scale studies of saline soils of the studied territory, allowed to identify the causes and patterns of formation, regional features of salt accumulation, as well as to establish the dependence of spatial differentiation of soil salinity on geological and geomorphological conditions. The dependence of soil salinization and their chemical composition on the movement of stream structures is established, which is reflected on the soil reclamation map. There is an alternation of unsalted (washed) soils (areas) with weak medium and strong, and sometimes very saline (salt marshes). It is revealed that the depth of the salt horizon (salt maximum), its power and the degree of salinity of the soil of objects represent a great variety, determined mainly by lithological-geomorphological, soil-reclamation and anthropogeniceconomic conditions. In saline (salt is found in a layer of $0-30 \mathrm{~cm}$ ). There are soils highly saline $(30-50 \mathrm{~cm})$, saline $(50-100 \mathrm{~cm})$, deep saline $(150-200 \mathrm{~cm})$ and unsalted (deeper than $200 \mathrm{~cm}$ ) differences. The number of salts in the profile of saline soils is different, often with several second-order maxima in layers of heavy mechanical composition. According to the content of water-soluble salts in the arable layer, the studied soils are mainly medium and highly saline, there are soils with a weak degree of salinity, and not infrequently there are saline soils with a salt content of $2-3$ to $8-9 \%$ with a chlorine content of $1.2-2.8 \%$. The total reserves of soil salts of the studied territories are extremely variegated and in the upper meter layer of soil their content ranges from 47-58 to $297-462 \mathrm{t} / \mathrm{ha}$.

The study was funded by the Uzbekistan Foundation of Basic Research, № 11.1.15. (System research on the genesis of irrigated saline soils in Uzbekistan, development of a set of measures (technologies) aimed at optimization and management of water-salt regime of the regions taking into account regional peculiarities. 


\section{References}

1. I. Abdullaev, S. Rakhmatullaev. Transformation of water management in Central Asia: From State-centric, hydraulic mission to socio-political control. Environ. Earth Sci. [73] (2015)

2. V. I. Antonov Water resources of Uzbekistan as part of the total water resources of the Aral Sea basin and their use in modern conditions and in the future. Water resources, problems of the Aral Sea and the environment. Collection of proceedings. (2000)

3. O. A. Borsuk Lithodynamic flows in river basins. Ecology of river basins: Proceedings of the [8] (2016).

4. E. A. Dmitriev Concepts of plastic relief and soil science soil science. [3] (1998).

5. M. Groll, Chr. Opp, R. Kulmatov, M. Ikramova I. Normatov, Water quality, potential conflicts and solutions - an upstream-downstream analysis of the transnational Zarafshan River (Tajikistan, Uzbekistan). Environ Earth Sci.(2013) DOI 10.1007/s12665-013-2988-5

6. K. W. F. Howard, K.K. Howard, The new "Silk Road Economic Belt" as a threat to the sustainable management of Central Asia's transboundary water resources. (2016)

7. V. M. Korsunov Methodology of soil ecological and geographical research and soil cartography //V.M.Korsunov, E.N.Kraseha, B.B.Raldin-Ulan-Ude: Publishing house of BNC SB RAS. (2002).

8. R. Kulmatov, M Groll, Ch. Opp, M. R. Rosen and D. Kulmatova, "Spatial and Temporal Changes of Transboundary Pollutants in the Zarafshan River, Uzbekistan," Water, Air and Soil Pollution (2012).

9. R. Kulmatov, Ch. Opp M. Groll, M. Kulmatova, Assessment of Water Quality of the Trans-Boundary Zarafshan River in the Territory of Uzbekistan. Journal of Water Resource and Protection (2013) doi:10.4236/jwarp.2013.51003

10. Method of plastic relief in thematic mapping. Pushchino: ONTI NCBI, 1987.

11. I. K. Nazarov, Abiogenic flows in arid geosystems: optimization of nature management (based on materials from the lower part of the Zarafshan river basin). (1992)

12. O. Ruzikulova Ways to improve methods of land-reclamation map of Zarafshan oasis. GOSNIIPA (2005).

13. N. I. Sabitova, Application of the method of relief plasticity in drawing up a map of groundwater mineralization. Method of plastic relief in thematic mapping. NCBI of the USSR Academy of Sciences (1987)

14. N. I. Sabitova, U.K. Abdunazarov, O.Sh. Ruzikulova, The role of topographic maps in identifying the formation of flow geosystems of the earth's surface of the Zarafshan river valley //Actual problems of geography: materials of the Republican scientific and practical conference. (2006).

15. N. I. Sabitova, A.U. Akhmedov, G.T. Parpiev, O.Sh. Ruzikulova, Geometric feature of morphological structure and water-salt regime of the middle and lower part of the Zarafshan river valley //New technologies that increase soil fertility: international scientific conference materials. - Tashkent: GOSNIIPA, 2004. - p. 85-88.

16. N. I. Sabitova, A.U. Akhmedov, O.Sh. Ruzikulova, System-structural analysis and mapping of soil-reclamation state of irrigated lands of intermountain valleys. Ways to improve the efficiency of irrigated agriculture (2016). 
17. N. I. Sabitova, O.U. Akhmedov, System analysis in the study of the reclamation state of soils (on the example of the Zarafshan river basin). Materials of the IV Congress of soil science and agrochemists of Uzbekistan. Tashkent GosNIIPA, 2005, -p. 94-104.

18. N. I. Sabitova, A.A. Neskhodimov, P.B. Neiman, Application of the method of relief plasticity to geomorphological zoning on the example of the Eastern part of the Zarafshan river valley //Uzbek geological journal. [4] (1990).

19. P. A. Shary, Topographical method of second derivatives. Collection of articles "Geometry of structures of the earth's surface". [1] (1991).

20. V. B. Sochava, Introduction to the doctrine of geosystems. - Novosibirsk: Science, 1978.

21. I. N. Stepanov, Space and time in the Sciences of soils. - Moscow: Science, (2003).

22. I. N. Stepanov, Theory of plastic relief and new thematic maps. Science (2006).

23. I. N. Stepanov, N.A. Loshakova, A.I. Satalkin, M.I. Andronova, Composing soil maps using the system cartographic method-plastic relief. Method of plastic relief in thematic mapping. Pushchino: NCBI of the USSR Academy of Sciences. (1987)

24. H. A. Toychiev, N.I. Sabitova, Plasticity of modern relief in solving geoecological problems on the example of the Eastern part of the Zarafshan river valley. Geoecologyproblems and prospects. (2000) 